\title{
Glucocorticoids and Preterm Hypoxic-Ischemic Brain Injury: The Good and the Bad
}

\author{
Laura Bennet, Joanne O. Davidson, Miriam Koome, and Alistair Jan Gunn \\ Fetal Physiology and Neuroscience Group, Department of Physiology, The University of Auckland, Auckland 1142, New Zealand \\ Correspondence should be addressed to Laura Bennet, 1.bennet@auckland.ac.nz \\ Received 27 March 2012; Accepted 13 July 2012 \\ Academic Editor: Janna Morrison \\ Copyright () 2012 Laura Bennet et al. This is an open access article distributed under the Creative Commons Attribution License, \\ which permits unrestricted use, distribution, and reproduction in any medium, provided the original work is properly cited.
}

Fetuses at risk of premature delivery are now routinely exposed to maternal treatment with synthetic glucocorticoids. In randomized clinical trials, these substantially reduce acute neonatal systemic morbidity, and mortality, after premature birth and reduce intraventricular hemorrhage. However, the overall neurodevelopmental impact is surprisingly unclear; worryingly, postnatal glucocorticoids are consistently associated with impaired brain development. We review the clinical and experimental evidence on how glucocorticoids may affect the developing brain and highlight the need for systematic research.

\section{Introduction}

Since Liggins and Howie [1] showed that antenatal glucocorticoids play an important role in the prevention of respiratory distress syndrome in premature infants, antenatal glucocorticoids have been increasingly given to women at risk of premature delivery. In 1994, the National Institutes of Health Consensus Conference stated that all fetuses between 24 and 34 weeks of gestation at risk of premature delivery should be considered candidates for treatment with antenatal glucocorticoids [2]. Meta-analysis of randomized clinical trials suggests that maternal treatment with antenatal glucocorticoids substantially reduces acute neonatal systemic morbidity, and mortality, after premature birth and reduces intraventricular hemorrhage [3]. There is some evidence from individual studies that treatment may also reduce the risk of white matter injury $[4,5]$.

\section{Cause for Concern?}

There is limited information on the short-term and longterm effects of antenatal glucocorticoids on the brain. From animal studies there is some evidence that antenatal glucocorticoids may cause impairment of neural development [6]. These side effects include alterations of neuronal cytoskeleton and presynaptic terminals [7-9], delay in myelination $[10,11]$, alterations in proliferation [12], decrease in cerebral blood flow [13], alterations in neuronal activity [14], and brain growth retardation [15].

In humans, antenatal glucocorticoids were associated with an increased risk of disorders in aggressive destructive behaviour, hyperactivity, and distractibility [16]. However, results are not consistent in different studies. MacArthur and colleagues $[17,18]$ found no effect of betamethasone treatment on cognitive development of 4-year-old children and cognitive development and school progress of 6-year-old children. After a 10- to 12-year followup, children who were treated with antenatal glucocorticoids did not differ from controls in growth, lung function, development of sexual characteristics, sleep quality, incidence of physical anomalies, and neurological status [19]. Murphy found no brain growth retardation in babies delivered preterm who died [20].

In contrast, there is now considerable experimental and clinical evidence that postnatal administration to preterm infants is consistently associated with impaired brain development [21]. In rodents glucocorticoids are associated with reduced proliferation and a decrease in total cell numbers, leading to impaired brain growth and development $[5,7-$ $9,12,15,22-28]$. Indeed, in rodents exposure to glucocorticoids before or immediately after birth may be associated with marked upregulation of neuronal and progenitor cell apoptosis, particularly in the hippocampus where they deplete the pool of neural progenitor cells and reduce 
hippocampal growth [29-31]. In turn, there is increasing evidence that exposure of neonates to exogenous glucocorticoids impairs memory and increases the risk of CP [32].

Pragmatically, the effects of prenatal and postnatal exposure are of course unlikely to be identical. The duration of maternal treatment is much shorter (typically 2 to 4 doses over $24 \mathrm{~h}$ versus 3 to 42 days of daily treatment [33]) and given the role of the placenta, it is likely that the profile of fetal plasma concentrations would be lower than after maternal administration compared with postnatal treatment. Nevertheless, these data strongly suggest that it is vital to understand how glucocorticoids affect the developing brain [22].

\section{Cerebral Palsy after Preterm Birth}

Cerebral palsy (CP) associated with premature birth now accounts for over a third of total cases [34]. The costs to society are huge. $\mathrm{CP}$ has one of the very highest indices of burden of disease from loss of potential productive members of society and direct burdens on the individual, family, and social institutions that last the entire life [35]. In the USA, $13 \%$ of all births are preterm, costing over $\$ 26.2$ billion in 2005 alone [36]. There has been little or no reduction in the incidence of $\mathrm{CP}$ of perinatal origin, and the risk may even have increased in some Western countries [36], despite 35 years of advances in perinatal care. Most of these costs are related to long-term neurodevelopmental disability in surviving infants, rather than acute care after birth [3739]. Although there has been a reduction in the most severe form of cystic white matter injury over time [40], even subtle injury is associated with impaired brain development and disability $[38,41]$. It is striking that risk of injury and disability are increased sevenfold even in "late preterm" infants of 34 to 36 weeks gestation [42-45]. Thus, even small changes in the risk of disability would have substantial realworld impact.

\section{What Causes Injury after Preterm Birth?}

Although the etiology of neurodevelopmental disability after preterm birth is undoubtedly multifactorial, there is considerable evidence that exposure to perinatal hypoxiaischemia (HI) is a major trigger [46]. In turn, this may be augmented or modulated by prior exposure to hypoxia, infection/inflammation, seizures, and placental damage [4752]. In addition, babies are exposed to many clinical interventions. Notably, unborn children are now routinely exposed to maternal treatment with potent synthetic glucocorticoids. Although steroid treatment is one of the most cost effective, live-saving treatments in fetal medicine, it is not without potential risks for some fetuses.

\section{Betamethasone versus Dexamethasone}

It has been much debated whether there is any material difference in neonatal outcomes between two major synthetic glucocorticoids used for antenatal treatment, despite these compounds differing only in the orientation of one methyl group. For example, it has been suggested that betamethasone, but not dexamethasone can reduce the risk of periventricular leukomalacia in very premature infants [4]. Further, betamethasone has been associated with better survival and reduced risk of adverse outcomes [53], and with better neurodevelopment and fewer hearing problems [54]. In contrast, others found no differences $[55,56]$, and one study suggested that dexamethasone reduced the risk for intraventricular hemorrhage more than betamethasone [56]. Conversely, betamethasone may have more pronounced effects to suppress fetal movements and heart rate variation $[46,47]$. Overall, there is a striking lack of information about the effects of these steroids on neural outcomes or fetal responses to hypoxia, and few formal comparisons have been performed.

\section{The Effects of Glucocorticoids on Postnatal Hypoxic-Ischemic Brain Injury}

The effect of glucocorticoids during and after $\mathrm{HI}$ in rodents appears to be rather variable. Clinically, glucocorticoids are used therapeutically to reduce brain edema, but clinical trials of glucocorticoids in ischemic stroke, intracerebral haemorrhage, aneurysmal subarachnoid haemorrhage, and traumatic brain injury have not shown any clear therapeutic effect [57]. Experimental studies of ischemia in adult rats or in vitro have generally suggested increased injury when glucocorticoids are given before the insult (range 1 to $48 \mathrm{~h}$ beforehand) [58-65]. Immediate pretreatment was reported to have no effect, whereas chronic postinsult treatment reduced injury in the caudate nucleus, but had no effect on other brain areas [60].

In contrast, in newborn rats at postnatal day 7 (P7), when brain maturation is equivalent to the mildly preterm infant $[66,67]$, preinsult treatment (4 to $48 \mathrm{~h}$ beforehand) significantly reduced injury [68-74]. In contrast, glucocorticoids were not protective if given just before ( 0 to $3 \mathrm{~h}$ ) or after HI $[68,75]$, and post-HI treatment increased mortality [75]. Antenatal treatment (on embryonic days 17, 18, and 19) has also been associated with reduced survival during hypoxia on the day after birth [76].

Injury may be mediated by reduced glucose uptake and energy utilization, accelerated ATP loss, and excessive $\mathrm{Ca}^{2+}$ mobilization during ischemia, and augmented excitotoxic and inflammatory responses post-ischemia $[59,61,62,77-$ 80]. Conversely, neuroprotection has been related to stabilizing ATP production, with maintenance of glycolytic flux $[70,81,82]$. There may be maturation dependent responses to glucocorticoids, dependent in part on cerebral metabolism [83-85]. In support of this, preischemic hyperglycemia reduced injury in P7 rats due to energy preservation [86-88].

However, this may well be a species dependent response as hyperglycemia increased injury in newborn piglets, despite energy preservation [89]. Postischemic hyperglycemia was not protective in either species [90, 91]. In adult animals glucose can increase, reduce or have no impact on injury $[58,59,92-99]$, and clinically it remains highly controversial 


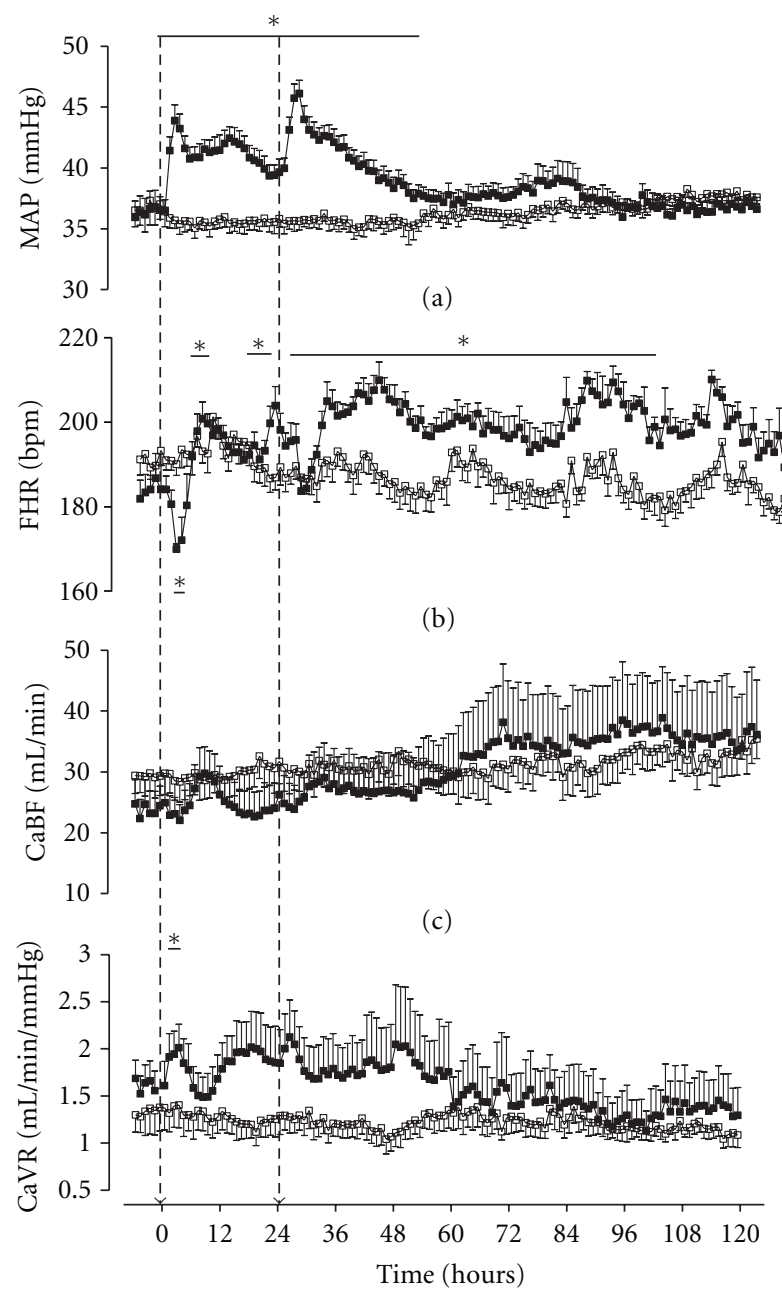

(d)

Figure 1: Time sequence of changes in mean arterial pressure (MAP), fetal heart rate (FHR), carotid blood flow (CaBF), and carotid vascular resistance (CaVR) in 0.7 gestation fetuses after two maternal intramuscular injections of either saline (open squares, $n=7$ ) or dexamethasone (filled squares, $n=8$ ). Dexamethasone induced a significant increase in MAP after each injection, and pressure was elevated for 50 hours. FHR fell acutely after each injection, and there was a sustained period of tachycardia after the second injection. There was a tendency for CaBF to fall initially, and this was associated with a significant rise in resistance. However, overall there were no marked differences in cerebral perfusion and resistance. Data are shown from six hours before the first injection to 120 hours afterwards. The dashed arrows show the timing of injections. Data are one hour averages, mean (SEM), ${ }^{*} P<0.05$.

whether controlling glucose affects outcomes after ischemia [100]. Nevertheless, maternal diabetes is associated with adverse neurodevelopmental outcomes in children, and this is strongly correlated with maternal hyperglycemia [101]. Further, hyperglycemia in preterm infants is associated with increased morbidity and mortality [102].

\section{How Do Glucocorticoids Affect the Fetus?}

Glucocorticoids are well documented to acutely affect fetal behaviour and cardiovascular function [103-106]. For example, a single clinical course of maternal dexamethasone in

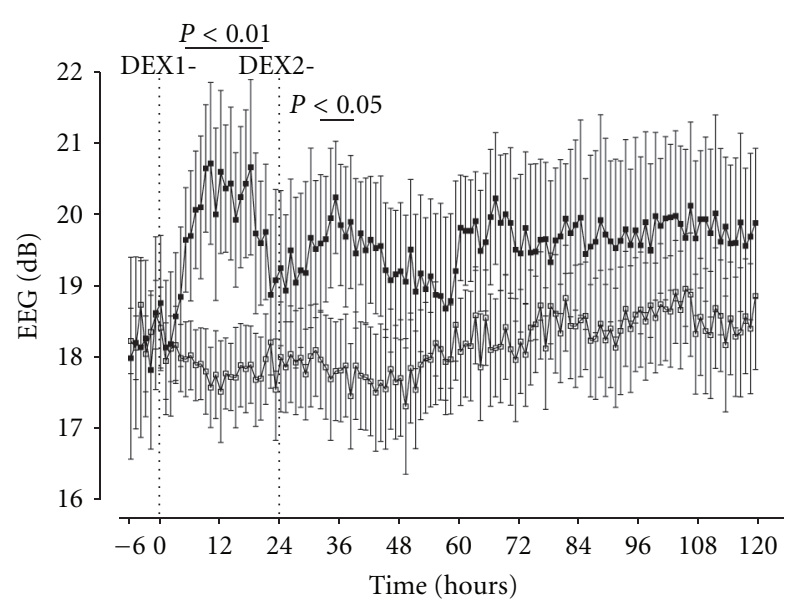

Figure 2: Time course changes in EEG power ( $\mathrm{dB}$, decibels) before and after two injections of dexamethasone (filled squares) or saline (open squares) 24 hours apart. The injections for each group are marked by dotted lines (DEX-1 and DEX-2). A significant increase in EEG power was seen after both DEX-1 and DEX2, but the effects of DEX were most significant after the first injection. Peak amplitude changes were around 12 hours, and the increase in amplitude was mediated by an overall increase in normal sleep architecture waveforms and the appearance of seizures (see Figure 3). Data are one hour means \pm SEM from six hours before until 120 hours after DEX-1.

sheep at 0.7 of gestation, when brain development is broadly consistent with the 28 to 32 week human fetus [107], was associated with an acute, transient increase in mean arterial blood pressure with a rise in carotid and femoral vascular resistance, a fall in femoral arterial blood flow, and a brief fall in fetal heart rate followed by tachycardia (Figure 1) [106]. There was a persistent loss of the circadian pattern of fetal heart rate variability 3 days after maternal dexamethasone. Similarly, in pregnant sheep near-term, when fetal brain development is broadly comparable to the term human $[107,108]$, a clinical regime of betamethasone was associated with reduced fetal cerebral perfusion and increased cerebral metabolic activity [109]. In preterm fetal sheep, a clinical dose of maternal dexamethasone reduced the number and duration of interburst intervals [110], with a commensurate increase in the continuity of the fetal EEG, suggesting that glucocorticoid exposure increased the functional maturation of the brain (Figures 2 and 3). Other effects include the intriguing finding in near-term fetal sheep that exposure to dexamethasone increased $\mathrm{Na}$-K-ATPase activity and tight junction expression $[111,112]$. This may be of significance, since in neonatal rats, treatment with dexamethasone before HI was associated with both reduced blood brain barrier leakage and reduced HI brain injury at P7 and P14, but not P21 [103].

There are no data on whether glucocorticoid exposure may affect the preterm fetal ability to adapt to hypoxia. However, in near-term fetal sheep maternal dexamethasone (2 maternal injections $24 \mathrm{~h}$ apart) before moderate isocapnic hypoxia, which does not cause overt neural injury, was associated with impaired cardiovascular responses, with significant bradycardia and increased acidosis during hypoxia 8 


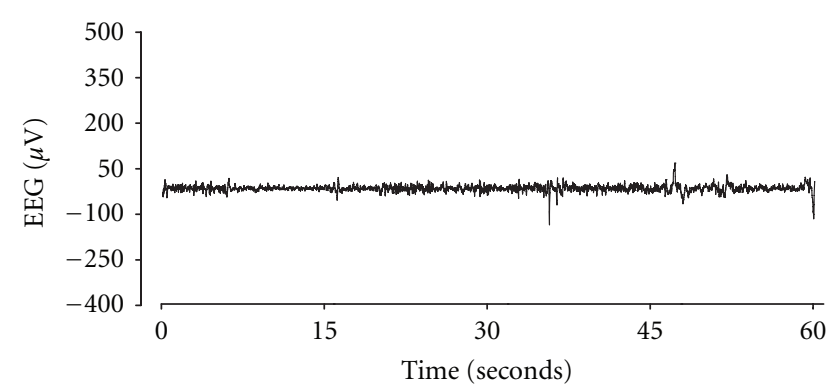

(a)

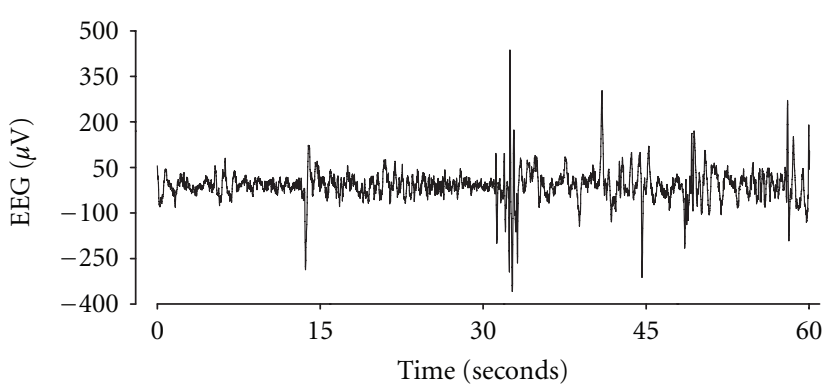

(b)

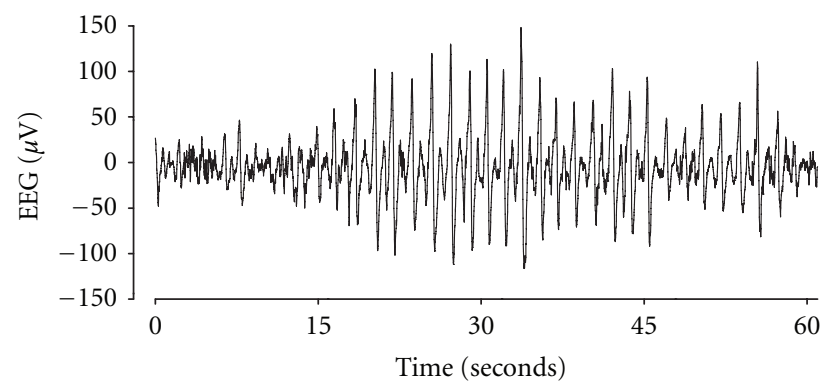

(c)

FIGURE 3: Example of sleep state architecture in a 0.7 gestation preterm fetal lamb before exposure to maternal dexamethasone (panel (a)) and after dexamethasone (panel (b)). The normal sleep patterns of fetal sheep at this age is composed of mixed EEG amplitudes and frequencies, with mean amplitude typically around $60-70 \mu \mathrm{V}$. Transient waveforms (fast, sharp, and slow waves between 70-400 ms) are seen as part of this normal EEG patterns and their amplitude is typically between $70-150 \mu \mathrm{V}$. After dexamethasone exposure, there is a significant change in sleep architecture characterised by a significant increase in EEG amplitude (with background amplitudes increased to above $100 \mu \mathrm{V}$ and spikes ranging between $200-600 \mu \mathrm{V}$ ), and a general reduction in high-frequency activity. Seizures and seizure-like activity is also observed and an example of this is shown in panel (c). While many of these seizures were high amplitude, it is notable that many were relatively low amplitude. All figures are raw data from one animal.

hours after the second injection, whereas there was no effect 3 days after the second injection [113, 114]. Despite suppression of hypothalamic-pituitary axis function [115], low doses of dexamethasone augmented the glycemic response to hypoxia in near-term sheep fetuses [116].

\section{The Effects of Glucocorticoids on Brain Activity in Preterm Fetal Sheep: A Potential Role for Conditioning?}

We recently demonstrated that a clinical course of maternal dexamethasone was associated with significant dysregulation of brain activity in healthy preterm fetal sheep, including a loss of the normal gating of EEG waveform amplitude, and induction of seizures (Figures 2 and 3) [110]. In this paradigm, fetal blood glucose transiently increased, peaking $\sim 4-6 \mathrm{~h}$ after maternal DEX treatment $[106,110]$. There was no cerebral injury after $5 \mathrm{~d}$ of recovery. Seizures in early life in the rat [117], and other settings [118], can induce neuroprotection against later injury through preconditioning mechanisms, for example, by inducing protective gene changes. Thus, it is plausible that this activity could be beneficial given the serious neural risks of preterm birth [36].

The caveat to this reassuring hypothesis is that after exposure to preconditioning insults, such as seizures, it typically takes several days before protection is established
[119-122]. If there are only a few hours between the stimulus and the HI insult, then sensitization occurs [119-122]. Thus, injury may occur with an otherwise noninjurious insult. In this setting both hyperglycemia and greater transient activity after glucocorticoid exposure could make the brain more vulnerable to HI. Epileptiform transients are associated with greater injury after $\mathrm{HI}$ in the preterm fetal sheep [123], likely by increasing the metabolic stress of injured cells making them vulnerable to further hypoxia [124]. Hyperglycemia increases glucose utilisation in the fetus [125], increasing neural metabolism and the metabolic demand on sick cells $[126,127]$. Again, although these data are not definitive, they suggest potential for risk.

\section{Glucocorticoids and HI in the Fetus}

Rather remarkably, given the established clinical use of glucocorticoids for threatened premature delivery, we have been able to identify only one study of their effects on $\mathrm{HI}$ injury in the fetus. In near-term fetal sheep, Ellit and colleagues reported that chronic pretreatment ( $48 \mathrm{~h}$ before ischemia induced by carotid artery occlusion) had no effect on subsequent ischemic brain injury [128]. In contrast, in cultured embryonic rat basal forebrain cells, exposure to dexamethasone before oxygen-glucose deprivation was associated with increased injury [77]; this damage could be 
negated by glutamate receptor blockade. Potentially these contrasting results between protection in rats, no effect in sheep, and increased injury in vitro, might be related to species or to the specific model of brain injury, or to lower plasma levels after maternal treatment compared to direct neonatal injection. It is also critical to appreciate that the dose response for the glucocorticoid effects on neuronal cell viability and survival is both narrow and U-shaped [129].

\section{Conclusions}

Given the frighteningly limited information on whether glucocorticoids protect or sensitise to HI brain injury in preterm fetuses [130] it is of considerable concern that glucocorticoids have been suggested to be potential perinatal neuroprotection agents $[84,85]$. The recent finding discussed above that a clinical course of maternal dexamethasone exposure triggers major changes in brain activity, including epileptiform events now raises the possibility that maternal glucocorticoids may well be both protective and damaging, depending on the precise timing before the preterm fetus and infant are exposed to an HI insult. These concepts suggest that as with so many aspects of neonatology timing is everything! [131] In turn, variations in timing of exposure may well explain the rather variable effects of maternal treatment in human clinical trials suggested above. Further systematic clinical and basic science studies are essential to tease out these factors.

\section{Acknowledgments}

This study was supported by the Health Research Council of New Zealand, The Auckland Medical Research Foundation, and the Lottery Grants Board of New Zealand.

\section{References}

[1] G. C. Liggins and R. N. Howie, "A controlled trial of antepartum glucocorticoid treatment for prevention of the respiratory distress syndrome in premature infants," Pediatrics, vol. 50, no. 4, pp. 515-525, 1972.

[2] L. C. Gilstrap, R. Christensen, W. H. Clewell et al., "Effect of corticosteroids for fetal maturation on perinatal outcomes," Journal of the American Medical Association, vol. 273, no. 5, pp. 413-418, 1995.

[3] D. Roberts and S. Dalziel, "Antenatal corticosteroids for accelerating fetal lung maturation for women at risk of preterm birth," Cochrane Database of Systematic Reviews, vol. 3, Article ID CD004454, 2006.

[4] O. Baud, L. Foix-L'Helias, M. Kaminski et al., "Antenatal glucocorticoid treatment and cystic periventricular leukomalacia in very premature infants," New England Journal of Medicine, vol. 341, no. 16, pp. 1190-1196, 1999.

[5] A. Whitelaw and M. Thoresen, "Antenatal steroids and the developing brain," Archives of Disease in Childhood, vol. 83, no. 2, pp. F154-F157, 2000.

[6] I. Antonow-Schlorke, A. Helgert, and C. Gey et al., "Adverse effects of antenatal glucocorticoids on cerebral myelination in sheep," Obstetrics \& Gynecology, vol. 113, no. 1, pp. 142151, 2009.
[7] M. Schwab, I. Antonow-Schlorke, B. Kühn et al., "Effect of antenatal betamethasone treatment on microtubule-associated proteins MAP1B and MAP2 in fetal sheep," Journal of Physiology, vol. 530, no. 3, pp. 497-506, 2001.

[8] I. Antonow-Schlorke, B. Kühn, T. Müller et al., "Antenatal betamethasone treatment reduces synaptophysin immunoreactivity in presynaptic terminals in the fetal sheep brain," Neuroscience Letters, vol. 297, no. 3, pp. 147-150, 2001.

[9] I. Antonow-Schlorke, M. Schwab, C. Li, and P. W. Nathanielsz, "Glucocorticoid exposure at the dose used clinically alters cytoskeletal proteins and presynaptic terminals in the fetal baboon brain," Journal of Physiology, vol. 547, no. 1, pp. 117-123, 2003.

[10] S. A. Dunlop, M. A. Archer, J. A. Quinlivan, L. D. Beazley, and J. P. Newnham, "Repeated prenatal corticosteroids delay myelination in the ovine Central Nervous System," Journal of Maternal-Fetal and Neonatal Medicine, vol. 6, no. 6, pp. 309313, 1997.

[11] W. L. Huang, C. G. Harper, S. F. Evans, J. P. Newnham, and S. A. Dunlop, "Repeated prenatal corticosteroid administration delays myelination of the corpus callosum in fetal sheep," International Journal of Developmental Neuroscience, vol. 19, no. 4, pp. 415-425, 2001.

[12] A. Scheepens, M. van de Waarenbug, D. van den Hove, and C. E. Blanco, "A single course of prenatal betamethasone in the rat alters postnatal brain cell proliferation but not apoptosis," Journal of Physiology, vol. 552, no. 1, pp. 163-175, 2003.

[13] M. Schwab, M. Roedel, M. Akhtar Anwar et al., "Effects of betamethasone administration to the fetal sheep in late gestation on fetal cerebral blood flow," Journal of Physiology, vol. 528, no. 3, pp. 619-632, 2000.

[14] M. Schwab, K. Schmidt, M. Roedel et al., "Non-linear changes of electrocortical activity after antenatal betamethasone treatment in fetal sheep," Journal of Physiology, vol. 531, no. 2, pp. 535-543, 2001.

[15] W. L. Huang, L. D. Beazley, J. A. Quinlivan, S. F. Evans, J. P. Newnham, and S. A. Dunlop, "Effect of corticosteroids on brain growth in fetal sheep," Obstetrics and Gynecology, vol. 94, no. 2, pp. 213-218, 1999.

[16] N. P. French, R. Hagan, S. F. Evans, A. Mullan, and J. P. Newnham, "Repeated antenatal corticosteroids: effects on cerebral palsy and childhood behavior," American Journal of Obstetrics and Gynecology, vol. 190, no. 3, pp. 588-595, 2004.

[17] B. A. MacArthur, R. N. Howie, J. A. Dezoete, and J. Elkins, "Cognitive and psychosocial development of 4-year-old children whose mothers were treated antenatally with betamethasone," Pediatrics, vol. 68, no. 5, pp. 638-643, 1981.

[18] B. A. MacArthur, R. N. Howie, J. A. Dezoete, and J. Elkins, "School progress and cognitive development of 6-yearold children whose mothers were treated antenatally with betamethasone," Pediatrics, vol. 70, no. 1, pp. 99-105, 1982.

[19] H. Smolders-De Haas, J. Neuvel, B. Schmand, P. E. Treffers, J. G. Koppe, and J. Hoeks, "Physical development and medical history of children who were treated antenatally with corticosteroids to prevent respiratory distress syndrome: a 10- to 12-year follow-up," Pediatrics, vol. 86, no. 1, pp. 65-70, 1990.

[20] D. J. Murphy, "Effect of antenatal corticosteroids on postmortem brain weight of preterm babies," Early Human Development, vol. 63, no. 2, pp. 113-122, 2001.

[21] E. W. Y. Tam, V. Chau, D. M. Ferriero et al., "Preterm birth: preterm cerebellar growth impairment after postnatal exposure to glucocorticoids," Science Translational Medicine, vol. 3, no. 105, p. 105ra105, 2011. 
[22] O. Baud and A. Sola, "Corticosteroids in perinatal medicine: how to improve outcomes without affecting the developing brain?" Seminars in Fetal and Neonatal Medicine, vol. 12, no. 4, pp. 273-279, 2007.

[23] E. S. Shinwell and S. Eventov-Friedman, "Impact of perinatal corticosteroids on neuromotor development and outcome: review of the literature and new meta-analysis," Seminars in Fetal and Neonatal Medicine, vol. 14, no. 3, pp. 164-170, 2009.

[24] N. Modi, H. Lewis, N. Al-Naqeeb, M. Ajayi-Obe, C. J. Dore, and M. Rutherford, "The effects of repeated antenatal glucocorticoid therapy on the developing brain," Pediatric Research, vol. 50, no. 5, pp. 581-585, 2001.

[25] A. Ali Khan, A. Rodriguez, M. Kaakinen, A. Pouta, A. L. Hartikainen, and M. R. Jarvelin, "Does in utero exposure to synthetic glucocorticoids influence birthweight, head circumference and birth length? A systematic review of current evidence in humans," Paediatric and Perinatal Epidemiology, vol. 25, no. 1, pp. 20-36, 2011.

[26] P. Leao, J. C. Sousa, M. Oliveira, R. Silva, O. F. X. Almeida, and N. Sousa, "Programming effects of antenatal dexamethasone in the developing mesolimbic pathways," Synapse, vol. 61, no. 1, pp. 40-49, 2007.

[27] H. Uno, L. Lohmiller, C. Thieme et al., "Brain damage induced by prenatal exposure to dexamethasone in fetal rhesus macaques-I. Hippocampus," Developmental Brain Research, vol. 53, no. 2, pp. 157-167, 1990.

[28] C. W. Noorlander, G. H. A. Visser, G. M. J. Ramakers, P. G. J. Nikkels, and P. N. E. De Graan, "Prenatal corticosteroid exposure affects hippocampal plasticity and reduces lifespan," Developmental Neurobiology, vol. 68, no. 2, pp. 237246, 2008.

[29] D. G. Zuloaga, D. L. Carbone, R. Hiroi, D. L. Chong, and R. J. Handa, "Dexamethasone induces apoptosis in the developing rat amygdala in an age-, region-, and sex-specific manner," Neuroscience, vol. 199, pp. 535-547, 2011.

[30] K. K. Noguchi, K. C. Walls, D. F. Wozniak, J. W. Olney, K. A. Roth, and N. B. Farber, "Acute neonatal glucocorticoid exposure produces selective and rapid cerebellar neural progenitor cell apoptotic death," Cell Death and Differentiation, vol. 15, no. 10, pp. 1582-1592, 2008.

[31] S. Yu, A. V. Patchev, Y. Wu et al., "Depletion of the neural precursor cell pool by glucocorticoids," Annals of Neurology, vol. 67, no. 1, pp. 21-30, 2010.

[32] S. K. Damsted, A. P. Born, O. B. Paulson, and P. Uldall, "Exogenous glucocorticoids and adverse cerebral effects in children," European Journal of Paediatric Neurology, vol. 15, no. 6, pp. 465-477, 2011.

[33] H. L. Halliday, R. A. Ehrenkranz, and L. W. Doyle, "Late (>7 days) postnatal corticosteroids for chronic lung disease in preterm infants," Cochrane Database of Systematic Reviews, no. 1, Article ID CD001145, 2009.

[34] Committee on Understanding Premature Birth and Assuring Healthy Outcomes, "Preterm Birth: Causes, Consequences, and Prevention," R. E. Behrman and A. S. Butler, Eds., Institute of Medicine, The National Academies Press, 2007, http://books.nap.edu//catalog/11622.html\#toc.

[35] Centers for Disease Control and Prevention (CDC), "Economic costs associated with mental retardation, cerebral palsy, hearing loss, and vision impairment-United States, 2003," Morbidity and Mortality Weekly Report, vol. 53, no. 3, pp. 57-59, 2004.
[36] Committee on Understanding Premature Birth and Assuring Healthy Outcomes, "Preterm Birth: Causes, Consequences, and Prevention," R. E. Behrman and A. S. Butler, Eds., Institute of Medicine of the National Academies, Washington, DC, USA, 2005.

[37] D. Wilson-Costello, H. Friedman, N. Minich, A. A. Fanaroff, and M. Hack, "Improved survival rates with increased neurodevelopmental disability for extremely low birth weight infants in the 1990s," Pediatrics, vol. 115, no. 4, pp. 997-1003, 2005.

[38] L. J. Woodward, P. J. Anderson, N. C. Austin, K. Howard, and T. E. Inder, "Neonatal MRI to predict neurodevelopmental outcomes in preterm infants," New England Journal of Medicine, vol. 355, no. 7, pp. 685-694, 2006.

[39] S. Saigal and L. W. Doyle, "An overview of mortality and sequelae of preterm birth from infancy to adulthood," The Lancet, vol. 371, no. 9608, pp. 261-269, 2008.

[40] S. E. G. Hamrick, S. P. Miller, C. Leonard et al., "Trends in severe brain injury and neurodevelopmental outcome in premature newborn infants: the role of cystic periventricular leukomalacia," Journal of Pediatrics, vol. 145, no. 5, pp. 593599, 2004.

[41] B. S. Peterson, B. Vohr, L. H. Staib et al., "Regional brain volume abnormalities and long-term cognitive outcome in preterm infants," Journal of the American Medical Association, vol. 284, no. 15, pp. 1939-1947, 2000.

[42] C. K. Shapiro-Mendoza, K. M. Tomashek, M. Kotelchuck et al., "Effect of late-preterm birth and maternal medical conditions on newborn morbidity risk," Pediatrics, vol. 121, no. 2, pp. e223-e232, 2008.

[43] S. S. Billiards, C. R. Pierson, R. L. Haynes, R. D. Folkerth, and H. C. Kinney, "Is the late preterm infant more vulnerable to gray matter injury than the term infant?" Clinics in Perinatology, vol. 33, no. 4, pp. 915-933, 2006.

[44] I. S. Baron, K. Erickson, M. D. Ahronovich, R. Baker, and F. R. Litman, "Cognitive deficit in preschoolers born latepreterm," Early Human Development, vol. 87, no. 2, pp. 115119, 2011.

[45] M. A. Woythaler, M. C. McCormick, and V. C. Smith, "Late preterm infants have worse 24-month neurodevelopmental outcomes than term infants," Pediatrics, vol. 127, no. 3, pp. e622-e629, 2011.

[46] J. A. Low, "Reflections on the occurrence and significance of antepartum fetal asphyxia," Best Practice and Research, vol. 18, no. 3, pp. 375-382, 2004.

[47] R. D. Barrett, L. Bennet, J. Davidson et al., "Destruction and reconstruction: hypoxia and the developing brain," Birth Defects Research Part C, vol. 81, no. 3, pp. 163-176, 2007.

[48] X. Wang, H. Hagberg, C. Nie, C. Zhu, T. Ikeda, and C. Mallard, "Dual role of intrauterine immune challenge on neonatal and adult brain vulnerability to hypoxia-ischemia," Journal of Neuropathology and Experimental Neurology, vol. 66, no. 6, pp. 552-561, 2007.

[49] S. Eklind, C. Mallard, A. L. Leverin et al., "Bacterial endotoxin sensitizes the immature brain to hypoxic-ischaemic injury," European Journal of Neuroscience, vol. 13, no. 6, pp. 1101-1106, 2001.

[50] A. Larouche, M. Roy, H. Kadhim, A. M. Tsanaclis, D. Fortin, and G. Sébire, "Neuronal injuries induced by perinatal hypoxic-ischemic insults are potentiated by prenatal exposure to lipopolysaccharide: animal model for perinatally acquired encephalopathy," Developmental Neuroscience, vol. 27, no. 2-4, pp. 134-142, 2005. 
[51] B. J. Stoll, N. I. Hansen, I. Adams-Chapman et al., "Neurodevelopmental and growth impairment among extremely low-birth-weight infants with neonatal infection," Journal of the American Medical Association, vol. 292, no. 19, pp. 23572365, 2004.

[52] J. A. Low, H. Killen, and E. J. Derrick, "Antepartum fetal asphyxia in the preterm pregnancy," American Journal of Obstetrics and Gynecology, vol. 188, no. 2, pp. 461-465, 2003.

[53] B. H. Lee, B. J. Stoll, S. A. McDonald, and R. D. Higgins, "Adverse neonatal outcomes associated with antenatal dexamethasone versus antenatal betamethasone," Pediatrics, vol. 117, no. 5, pp. 1503-1510, 2006.

[54] B. H. Lee, B. J. Stoll, S. A. McDonald, and R. D. Higgins, "Neurodevelopmental outcomes of extremely low birth weight infants exposed prenatally to dexamethasone versus betamethasone," Pediatrics, vol. 121, no. 2, pp. 289-296, 2008.

[55] M. R. R. Bar-Lev, A. Maayan-Metzger, I. Matok, Z. Heyman, E. Sivan, and J. Kuint, "Short-term outcomes in low birth weight infants following antenatal exposure to betamethasone versus dexamethasone," Obstetrics and Gynecology, vol. 104, no. 3, pp. 484-488, 2004.

[56] A. Elimian, D. Garry, R. Figueroa, A. Spitzer, V. Wiencek, and J. G. Quirk, "Antenatal betamethasone compared with dexamethasone (Betacode trial): a randomized controlled trial," Obstetrics and Gynecology, vol. 110, no. 1, pp. 26-30, 2007.

[57] P. A. Sandercock and T. Soane, "Corticosteroids for acute ischaemic stroke," Cochrane Database of Systematic Reviews, vol. 9, Article ID CD000064, 2011.

[58] V. L. Smith-Swintosky, L. C. Pettigrew, R. M. Sapolsky et al., "Metyrapone, an inhibitor of glucocorticoid production, reduces brain injury induced by focal and global ischemia and seizures," Journal of Cerebral Blood Flow and Metabolism, vol. 16, no. 4, pp. 585-598, 1996.

[59] R. M. Sapolsky and W. A. Pulsinelli, "Glucocorticoids potentiate ischemic injury to neurons: therapeutic implications," Science, vol. 229, no. 4720, pp. 1397-1400, 1985.

[60] T. Koide, T. W. Wieloch, and B. K. Siesjo, "Chronic dexamethasone pretreatment aggravates ischemic neuronal necrosis," Journal of Cerebral Blood Flow and Metabolism, vol. 6, no. 4, pp. 395-404, 1986.

[61] R. M. Sapolsky, "Glucocorticoids, hippocampal damage and the glutamatergic synapse," Progress in Brain Research, vol. 86, pp. 13-23, 1990.

[62] N. Adachi, J. Chen, K. Liu, S. Tsubota, and T. Arai, "Dexamethasone aggravates ischemia-induced neuronal damage by facilitating the onset of anoxic depolarization and the increase in the intracellular Ca2+ concentration in gerbil hippocampus," Journal of Cerebral Blood Flow and Metabolism, vol. 18, no. 3, pp. 274-280, 1998.

[63] N. Adachi, C. Namba, T. Nagaro, and T. Arai, "Dexamethasone reduces energy utilization in ischemic gerbil brain," European Journal of Pharmacology, vol. 427, no. 2, pp. 119$123,2001$.

[64] S. Tsubota, N. Adachi, J. Chen, T. Yorozuya, T. Nagaro, and T. Arai, "Dexamethasone changes brain monoamine metabolism and aggravates ischemic neuronal damage in rats," Anesthesiology, vol. 90, no. 2, pp. 515-523, 1999.

[65] M. Y. Cheng, G. Sun, M. Jin, H. Zhao, G. K. Steinberg, and R. M. Sapolsky, "Blocking glucocorticoid and enhancing estrogenic genomic signaling protects against cerebral ischemia," Journal of Cerebral Blood Flow and Metabolism, vol. 29, no. 1, pp. 130-136, 2009.
[66] H. J. Romijn, M. A. Hofman, and A. Gramsbergen, "At what age is the developing cerebral cortex of the rat comparable to that of the full-term newborn human baby?" Early Human Development, vol. 26, no. 1, pp. 61-67, 1991.

[67] J. M. Dean, M. D. Moravec, M. Grafe et al., "Strain-specific differences in perinatal rodent oligodendrocyte lineage progression and its correlation with human," Developmental Neuroscience, vol. 33, no. 3-4, pp. 251-260, 2011.

[68] J. D. E. Barks, M. Post, and U. I. Tuor, "Dexamethasone prevents hypoxic-ischemic brain damage in the neonatal rat," Pediatric Research, vol. 29, no. 6, pp. 558-563, 1991.

[69] Y. Feng, P. G. Rhodes, and A. J. Bhatt, "Dexamethasone pre-treatment protects brain against hypoxic-ischemic injury partially through up-regulation of vascular endothelial growth factor A in neonatal rats," Neuroscience, vol. 179, pp. 223-232, 2011.

[70] B. J. Dardzinski, S. L. Smith, J. Towfighi, G. D. Williams, R. C. Vannucci, and M. B. Smith, "Increased plasma betahydroxybutyrate, preserved cerebral energy metabolism, and amelioration of brain damage during neonatal hypoxia ischemia with dexamethasone pretreatment," Pediatric Research, vol. 48, no. 2, pp. 248-255, 2000.

[71] P. D. Chumas, M. R. Del Bigio, J. M. Drake, and U. I. Tuor, "A comparison of the protective effect of dexamethasone to other potential prophylactic agents in a neonatal rat model of cerebral hypoxia-ischemia," Journal of Neurosurgery, vol. 79, no. 3, pp. 414-420, 1993.

[72] T. Ikeda, K. Mishima, N. Aoo et al., "Dexamethasone prevents long-lasting learning impairment following a combination of lipopolysaccharide and hypoxia-ischemia in neonatal rats," American Journal of Obstetrics and Gynecology, vol. 192, no. 3, pp. 719-726, 2005.

[73] K. Felszeghy, G. Banisadr, W. Rostène, C. Nyakas, and F. Haour, "Dexamethasone downregulates chemokine receptor CXCR4 and exerts neuroprotection against hypoxia/ ischemia-induced brain injury in neonatal rats," NeuroImmunoModulation, vol. 11, no. 6, pp. 404-413, 2004.

[74] P. Ekert, N. MacLusky, X. P. Luo et al., "Dexamethasone prevents apoptosis in a neonatal rat model of hypoxicischemic encephalopathy (HIE) by a reactive oxygen speciesindependent mechanism," Brain Research, vol. 747, no. 1, pp. 9-17, 1997.

[75] D. I. Altman, R. S. K. Young, and S. K. Yagel, "Effects of dexamethasone in hypoxic-ischemic brain injury in the neonatal rat," Biology of the Neonate, vol. 46, no. 3, pp. 149156, 1984.

[76] K. S. Kauffman, F. J. Seidler, and T. A. Slotkin, "Prenatal dexamethasone exposure causes loss of neonatal hypoxia tolerance: cellular mechanisms," Pediatric Research, vol. 35, no. 5, pp. 515-522, 1994.

[77] M. P. Flavin, "Influence of dexamethasone on neurotoxicity caused by oxygen and glucose deprivation in vitro," Experimental Neurology, vol. 139, no. 1, pp. 34-38, 1996.

[78] S. F. Sorrells, J. R. Caso, C. D. Munhoz, and R. M. Sapolsky, "The stressed CNS: when glucocorticoids aggravate inflammation," Neuron, vol. 64, no. 1, pp. 33-39, 2009.

[79] M. Kadekaro, M. Ito, and P. M. Gross, "Local cerebral glucose utilization is increased in acutely adrenalectomized rats," Neuroendocrinology, vol. 47, no. 4, pp. 329-334, 1988.

[80] H. C. Horner, D. R. Packan, and R. M. Sapolsky, "Glucocorticoids inhibit glucose transport in cultured hippocampal neurons and glia," Neuroendocrinology, vol. 52, no. 1, pp. 5764, 1990 . 
[81] U. I. Tuor, J. Y. Yager, S. Bascaramurty, and M. R. Del Bigio, "Dexamethasone prevents hypoxia/ischemia-induced reductions in cerebral glucose utilization and high-energy phosphate metabolites in immature brain," Journal of Neurochemistry, vol. 69, no. 5, pp. 1954-1963, 1997.

[82] R. C. Vannucci, R. M. Brucklacher, and S. J. Vannucci, "Glycolysis and perinatal hypoxic-ischemic brain damage," Developmental Neuroscience, vol. 27, no. 2-4, pp. 185-190, 2005.

[83] R. C. Vannucci and S. J. Vannucci, "Glucose metabolism in the developing brain," Seminars in Perinatology, vol. 24, no. 2, pp. 107-115, 2000.

[84] U. I. Tuor, "Glucocorticoids and the prevention of hypoxicischemic brain damage," Neuroscience and Biobehavioral Reviews, vol. 21, no. 2, pp. 175-179, 1997.

[85] J. M. Perlman, "Antenatal glucocorticoid, magnesium exposure, and the prevention of brain injury of prematurity," Seminars in Pediatric Neurology, vol. 5, no. 3, pp. 202-210, 1998.

[86] T. M. Voorhies, D. Rawlinson, and R. C. Vannucci, "Glucose and perinatal hypoxic-ischemic brain damage in the rat," Neurology, vol. 36, no. 8, pp. 1115-1118, 1986.

[87] R. C. Vannucci, "Cerebral carbohydrate and energy metabolism in perinatal hypoxic-ischemic brain damage," Brain Pathology, vol. 2, no. 3, pp. 229-234, 1992.

[88] R. C. Vannucci and D. J. Mujsce, "Effect of glucose on perinatal hypoxic-ischemic brain damage," Biology of the Neonate, vol. 62, no. 4, pp. 215-224, 1992.

[89] M. H. LeBlanc, M. Huang, V. Vig, D. Patel, E. E. Smith, and D. W. Busija, "Glucose affects the severity of hypoxic-ischemic brain injury in newborn pigs," Stroke, vol. 24, no. 7, pp. 10551062, 1993.

[90] R. A. Sheldon, J. C. Partridge, and D. M. Ferriero, "Postischemic hyperglycemia is not protective to the neonatal rat brain," Pediatric Research, vol. 32, no. 4, pp. 489-493, 1992.

[91] M. H. LeBlanc, M. Huang, D. Patel, E. E. Smith, and M. Devidas, "Glucose given after hypoxic ischemia does not affect brain injury in piglets," Stroke, vol. 25, no. 7, pp. 14431448, 1994.

[92] M. Nedergaard, R. P. Kraig, J. Tanabe, and W. A. Pulsinelli, "Dynamics of interstitial and intracellular $\mathrm{pH}$ in evolving brain infarct," American Journal of Physiology, vol. 260, no. 3, pp. R581-R588, 1991.

[93] A. Schurr, "Bench-to-bedside review: a possible resolution of the glucose paradox of cerebral ischemia," Critical Care, vol. 6, no. 4, pp. 330-334, 2002.

[94] M. Nedergaard, A. Gjedde, and N. H. Diemer, "Hyperglycaemia protects against neuronal injury around experimental brain infarcts," Neurological Research, vol. 9, no. 4, pp. 241244, 1987.

[95] S. Y. Seo, E. Y. Kim, H. Kim, I. Jou, and B. J. Gwag, "Attenuation of neuronal death by NMDA and oxygen-glucose deprivation in cortical neurons maintained in high glucose," Annals of the New York Academy of Sciences, vol. 893, pp. 396399, 1999.

[96] G. F. Tian and A. J. Baker, "Glycolysis prevents anoxiainduced synaptic transmission damage in rat hippocampal slices," Journal of Neurophysiology, vol. 83, no. 4, pp. 18301839, 2000.

[97] M. D. Ginsbery, R. Prado, and W. D. Dietrich, "Hyperglycemia reduces the extent of cerebral infarction in rats," Stroke, vol. 18, no. 3, pp. 570-574, 1987.
[98] M. A. Zasslow, R. G. Pearl, L. M. Shuer, G. K. Steinberg, R. E. Lieberson, and C. P. Larson, "Hyperglycemia decreases acute neuronal ischemic changes after middle cerebral artery occlusion in cats," Stroke, vol. 20, no. 4, pp. 519-523, 1989.

[99] U. I. Tuor and M. R. Del Bigio, "Protection against hypoxicischemic damage with corticosterone and dexamethasone: inhibition of effect by a glucocorticoid antagonist, RU38486," Brain Research, vol. 743, no. 1-2, pp. 258-262, 1996.

[100] S. Mehta, "The glucose paradox of cerebral ischaemia," Journal of Postgraduate Medicine, vol. 49, no. 4, pp. 299-301, 2003.

[101] A. Ornoy, "Growth and neurodevelopmental outcome of children born to mothers with pregestational and gestational diabetes," Pediatric Endocrinology Reviews, vol. 3, no. 2, pp. 104-113, 2005.

[102] A. L. Ogilvy-Stuart and K. Beardsall, "Management of hyperglycaemia in the preterm infant," Archives of Disease in Childhood, vol. 95, no. 2, pp. F126-F131, 2010.

[103] E. J. H. Mulder, R. de Heus, and G. H. A. Visser, "Antenatal corticosteroid therapy: short-term effects on fetal behaviour and haemodynamics," Seminars in Fetal and Neonatal Medicine, vol. 14, no. 3, pp. 151-156, 2009.

[104] E. J. H. Mulder, J. B. Derks, and G. H. A. Visser, "Antenatal corticosteroid therapy and fetal behaviour: a randomised study of the effects of betamethasone and dexamethasone," British Journal of Obstetrics and Gynaecology, vol. 104, no. 11, pp. 1239-1247, 1997.

[105] L. Bennet, S. Kozuma, H. H. G. McGarrigle, and M. A. Hanson, "Temporal changes in fetal cardiovascular, behavioural, metabolic and endocrine responses to maternally administered dexamethasone in the late gestation fetal sheep," British Journal of Obstetrics and Gynaecology, vol. 106, no. 4, pp. 331339, 1999.

[106] J. S. Quaedackers, V. Roelfsema, M. Fraser, A. J. Gunn, and L. Bennet, "Cardiovascular and endocrine effects of a single course of maternal dexamethasone treatment in preterm fetal sheep," British Journal of Obstetrics and Gynaecology, vol. 112, no. 2, pp. 182-191, 2005.

[107] R. M. Barlow, "The foetal sheep: morphogenesis of the nervous system and histochemical aspects of myelination," Journal of Comparative Neurology, vol. 135, no. 3, pp. 249262, 1969.

[108] G. H. McIntosh, K. I. Baghurst, B. J. Potter, and B. S. Hetzel, "Foetal brain development in the sheep," Neuropathology and Applied Neurobiology, vol. 5, no. 2, pp. 103-114, 1979.

[109] J. McCallum, N. Smith, M. Schwab et al., "Effects of antenatal glucocorticoids on cerebral substrate metabolism in the preterm ovine fetus," American Journal of Obstetrics and Gynecology, vol. 198, no. 1, pp. e101-e109, 2008.

[110] J. O. Davidson, J. S. L. T. Quaedackers, S. A. George, A. J. Gunn, and L. Bennet, "Maternal dexamethasone and EEG hyperactivity in preterm fetal sheep," Journal of Physiology, vol. 589, no. 15, pp. 3823-3835, 2011.

[111] N. S. Mehter, G. B. Sadowska, S. N. Malaeb, and B. S. Stonestreet, "Na+, K+-ATPase activity and subunit isoform protein abundance: effects of antenatal glucocorticoids in the frontal cerebral cortex and renal cortex of ovine fetuses," Reproductive Sciences, vol. 16, no. 3, pp. 294-307, 2009.

[112] G. B. Sadowska, S. N. Malaeb, and B. S. Stonestreet, "Maternal glucocorticoid exposure alters tight junction protein expression in the brain of fetal sheep," American Journal of Physiology, vol. 298, no. 1, pp. H179-H188, 2010.

[113] J. K. Jellyman, D. S. Gardner, C. M. B. Edwards, A. L. Fowden, and D. A. Giussani, "Fetal cardiovascular, metabolic 
and endocrine responses to acute hypoxaemia during and following maternal treatment with dexamethasone in sheep," Journal of Physiology, vol. 567, no. 2, pp. 673-688, 2005.

[114] A. J. W. Fletcher, D. S. Gardner, C. M. B. Edwards, A. B. Fowden, and D. A. Giussani, "Cardiovascular and endocrine responses to acute hypoxaemia during and following dexamethasone infusion in the ovine fetus," Journal of Physiology, vol. 549, no. 1, pp. 271-287, 2003.

[115] J. K. Jellyman, D. S. Gardner, H. H. G. McGarrigle, A. L. Fowden, and D. A. Giussani, "Pituitary-adrenal responses to acute hypoxemia during and after maternal dexamethasone treatment in sheep," Pediatric Research, vol. 56, no. 6, pp. 864-872, 2004.

[116] A. J. W. Fletcher, M. R. Goodfellow, A. J. Forhead et al., "Low doses of dexamethasone suppress pituitary-adrenal function but augment the glycemic response to acute hypoxemia in fetal sheep during late gestation," Pediatric Research, vol. 47, no. 5, pp. 684-691, 2000.

[117] A. Saghyan, G. N. LaTorre, R. Keesey et al., "Glutamatergic and morphological alterations associated with early life seizure-induced preconditioning in young rats," European Journal of Neuroscience, vol. 32, no. 11, pp. 1897-1911, 2010.

[118] E. M. Jimenez-Mateos and D. C. Henshall, "Seizure preconditioning and epileptic tolerance: models and mechanisms," International Journal of Physiology, Pathophysiology and Pharmacology, vol. 1, no. 2, pp. 180-191, 2009.

[119] U. Dirnagl, K. Becker, and A. Meisel, "Preconditioning and tolerance against cerebral ischaemia: from experimental strategies to clinical use," The Lancet Neurology, vol. 8, no. 4, pp. 398-412, 2009.

[120] U. Dirnagl and A. Meisel, "Endogenous neuroprotection: mitochondria as gateways to cerebral preconditioning?" Neuropharmacology, vol. 55, no. 3, pp. 334-344, 2008.

[121] R. D. Sanders, H. J. Manning, N. J. Robertson et al., "Preconditioning and postinsult therapies for perinatal hypoxicischemic injury at term," Anesthesiology, vol. 113, no. 1, pp. 233-249, 2010.

[122] H. Hagberg, P. Gressens, and C. Mallard, "Inflammation during fetal and neonatal life: implications for neurologic and neuropsychiatric disease in children and adults," JAnnals of Neurology, vol. 71, no. 4, pp. 444-457, 2012.

[123] L. Bennet, L. Booth, and A. J. Gunn, "Potential biomarkers for hypoxic-ischemic encephalopathy," Seminars in Fetal and Neonatal Medicine, vol. 15, no. 5, pp. 253-260, 2010.

[124] W. R. Selman, W. D. Lust, S. Pundik, Y. Zhou, and R. A. Ratcheson, "Compromised metabolic recovery following spontaneous spreading depression in the penumbra," Brain Research, vol. 999, no. 2, pp. 167-174, 2004.

[125] W. W. Hay Jr., S. A. Myers, and J. W. Sparks, "Glucose and lactate oxidation rates in the fetal lamb," Proceedings of the Society for Experimental Biology and Medicine, vol. 173, no. 4, pp. 553-563, 1983.

[126] R. G. Shulman, F. Hyder, and D. L. Rothman, "Cerebral energetics and the glycogen shunt: neurochemical basis of functional imaging," Proceedings of the National Academy of Sciences of the United States of America, vol. 98, no. 11, pp. 6417-6422, 2001.

[127] Z. Wang, W. Luo, P. Li, J. Qiu, and Q. Luo, "Acute hyperglycemia compromises cerebral blood flow following cortical spreading depression in rats monitored by laser speckle imaging," Journal of Biomedical Optics, vol. 13, no. 6, Article ID 064023, 2008.

[128] C. M. Elitt, G. B. Sadowska, E. G. Stopa, H. Pinar, K. H. Petersson, and B. S. Stonestreet, "Effects of antenatal steroids on ischemic brain injury in near-term ovine fetuses," Early Human Development, vol. 73, no. 1-2, pp. 1-15, 2003.

[129] I. M. Abraham, P. Meerlo, and P. G. Luiten, "Concentration dependent actions of glucocorticoids on neuronal viability and survival," Dose-Response, vol. 4, pp. 38-54, 2006.

[130] W. D. Lust, S. Pundik, J. Zechel, Y. Zhou, M. Buczek, and W. R. Selman, "Changing metabolic and energy profiles in fetal, neonatal, and adult rat brain," Metabolic Brain Disease, vol. 18, no. 3, pp. 195-206, 2003.

[131] A. J. Gunn and L. Bennet, "Hypothermia in the management of hypoxic-ischemic encephalopathy," NeoReviews, vol. 3, pp. e116-e122, 2002. 


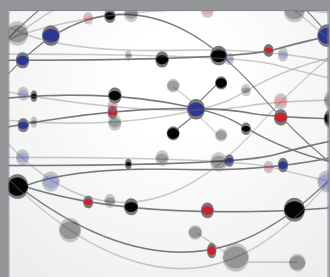

The Scientific World Journal
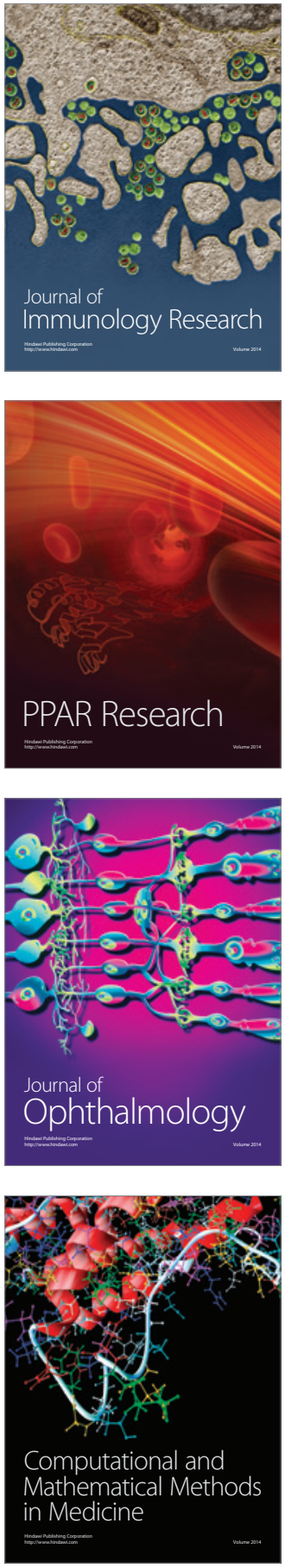

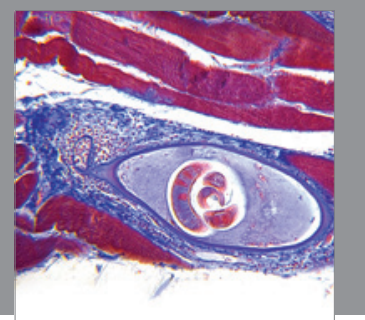

Gastroenterology

Research and Practice
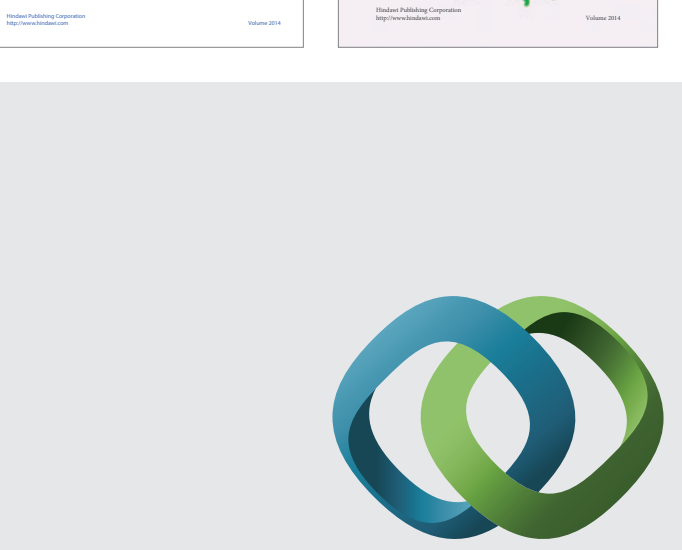

\section{Hindawi}

Submit your manuscripts at

http://www.hindawi.com
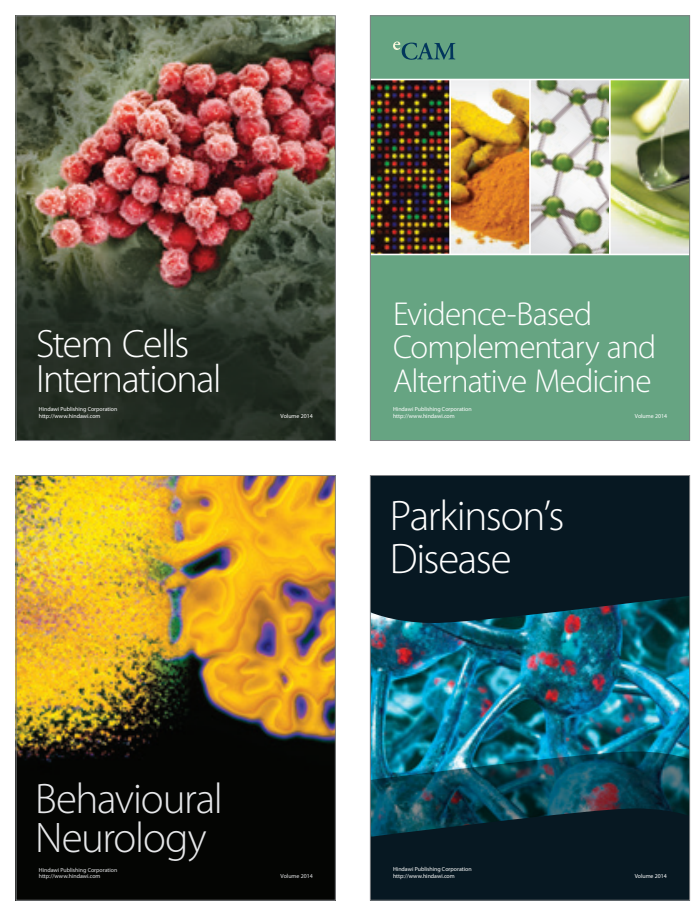

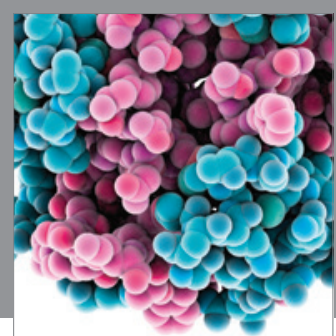

Journal of
Diabetes Research

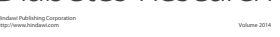

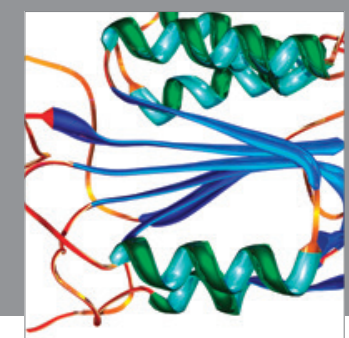

Disease Markers
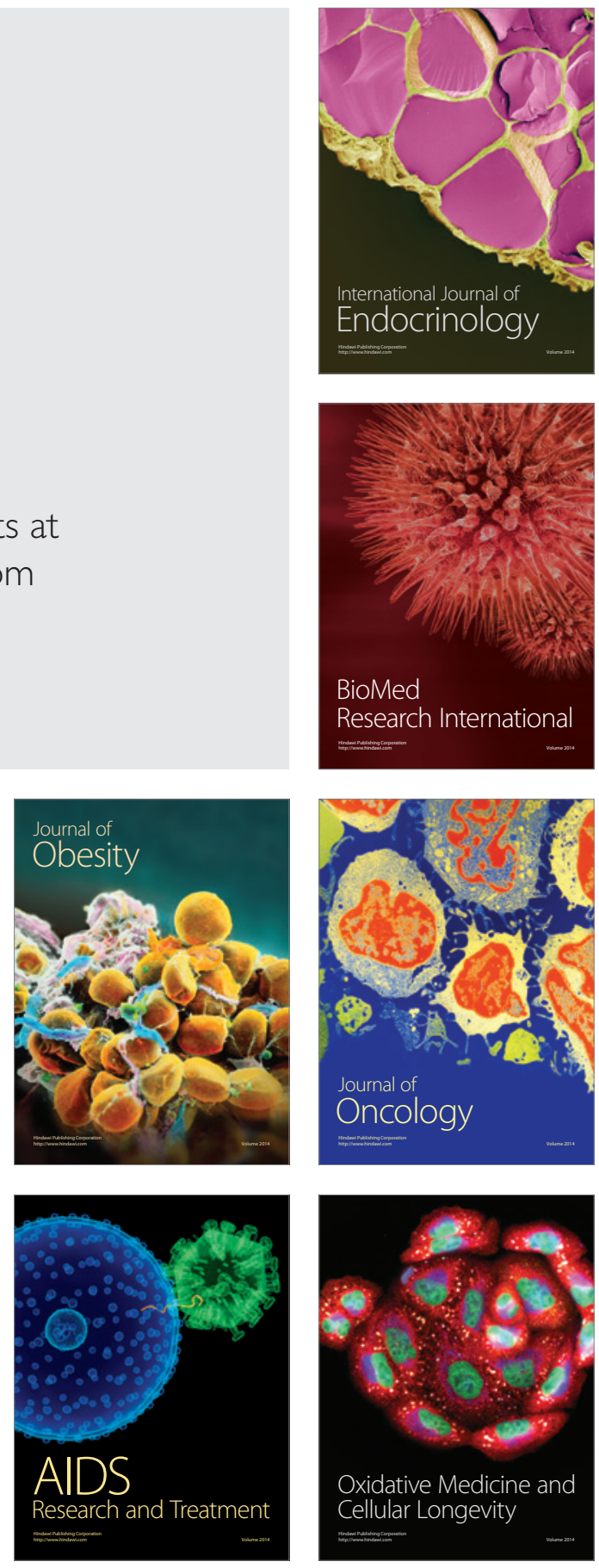